\title{
CHARACTERIZATION OF SOUTH INDIAN PADDY VARIETIES UNDER COMMERCIAL CULTIVATION THROUGH MORPHOLOGICAL AND MOLECULAR MARKERS
}

\author{
R.VIGNESHWARI ${ }^{1}$, A.VIJAYAKUMAR ${ }^{2} \&$ M.RAVEENDRAN ${ }^{3}$ \\ ${ }^{1,2}$ Department of Seed Science and Technology, Tamil Nadu Agricultural University, Coimbatore, Tamilnadu, India \\ ${ }^{3}$ Department of Plant Biotechnology, Tamil Nadu Agricultural University, Coimbatore, Tamilnadu, India
}

ABSTRACT
Rice varieties under commercial cultivation of Tamil Nadu, were characterized morphologically and also using
SSR markers, selected from 12 linkage groups of the rice genome. In case of morphological characters, the level of
discrimination was high in quantitative grain characters compared to qualitative characters. Cluster analysis based on
morphological characters, grouped the varieties of medium and long, slender grain type in one cluster and short bold
grain type into another cluster at about $65 \%$ similarity level. In SSR characterization polymorphism information content
(PIC) of the markers varied from 0.142 to 0.792 , with an average of 0.453 . The cluster analysis of SSR markers grouped
the varieties into four major clusters at a similar level of 35\%. The clustering, pattern showed some relationship with the
pedigree of the thirteen rice varieties. The results revealed that the SSR markers are highly efficient in generation of
unique DNA profiles of paddy varieties, which could be effectively utilized in assessing the seed genetic purity.
KEYWORDS: Rice, Morphological, SSR Markers \& Polymorphism

Received: Jun 25 2017; Accepted: Jul 15 2017; Published: Jul 27 2017; Paper Id.: IJASRAUG201759

\section{INTRODUCTION}

Rice is a major food crop ranking second to wheat, among the most cultivated cereals in the world. India is the second largest producer of rice, accounting for $20 \%$ of all world rice production from $24 \%$ of gross cropped area of the country. Among the major rice producing states of India, Tamil Nadu ranks fifth with the contribution of $7.0 \%$ with the annual production of 74.58 lakh tonnes from 19.0 lakh ha. Rice demand is expected to increase dramatically in the near future, due to several reasons like reduction in rice growing areas, increase population, climate, change, etc. The expected production can be achieved by the use of high yielding improved varieties. The success of improved variety in the farmer's field, depends on the availability of seeds with high genetic purity (Agarwal, 1999). A well selected variety has steadily maintained its hereditary qualities, over several generations. However, varietal deterioration often takes place at all stages of seed multiplication from sowing to harvest and even during post harvest operation. So, repeated use of seeds from generation to generation without renovation would lead to breakdown of varietal identity or genetic purity.

This necessitates the renovation and multiplication of seeds through generation system. For which a database that differentiate the variety of interest from other varieties of same species or off types is required. Morphological and agronomic traits have long been the means of studying classification and variability among populations and species. But identification of morphological markers not only requires a long procedure, but also less reliable, as many characters of interest have low heritability and genetically complex. Therefore, the morphological 
characterization needs the support of molecular markers. Molecular markers can provide a clear picture about the genetic relationship. Furthermore, DNA markers are 'neutral', and they have no effect on phenotype, no epistatic effect, and are not influenced by environmental conditions and developmental stages.

SSR marker analysis based on the availability of more than 2500 SSR loci covering the entire rice genome can remain as the future viable strategy for the marker based varietal profiling in rice and extending the same to the purity analysis (Ravi et al., 2003). With this background and seed technological viewpoint a study was conducted to discriminate the major paddy varieties in the commercial cultivation and exploring the advantage of molecular markers over morphological markers in seed purity testing.

\section{MATERIALS AND METHODS}

\section{Morphological Characterization}

The experimental material consists of thirteen paddy varieties in the commercial cultivation of rice belts of Tamil Nadu (Table 1). The trial was conducted as per the National Test Guidelines for Distinctness, Uniformity and Stability (DUS). Observations were recorded on ten randomly chosen plants of each variety per replication on appropriate growth stage for thirty one morphological traits.

\section{SSR Characterization}

\section{Genomic DNA Extraction}

DNA was isolated from leaf samples of 15 days old seedlings using CTAB method (Dellaporta et al., 1983). DNA was quantified using NanoDrop, ND-1000 spectrophotometer (JH BIO Innovations Pvt. Ltd, Bangalore). More than 200 microsatellite primer pairs covering all the chromosomes from genome database, Rice Genome Microsatellite Markers (http://www.gramene.org/db/markers.html) were used for this study.

\section{PCR Amplification}

PCRs were performed in $15 \mu \mathrm{l}$ reactions as described by Panaud et al. (1996) containing $1.0 \mu \mathrm{M}$ of each forward and reverse primers, $2.5 \mathrm{mM}$ of each dNTPs, $50 \mathrm{mM} \mathrm{KCl}, 10 \mathrm{mM}$ Tris $\mathrm{HCl}(\mathrm{pH} 8.3), 1.5 \mathrm{mM} \mathrm{MgCl} 2,0.01$ per cent gelatin, $40 \mathrm{ng}$ of DNA and 5 unit of Taq DNA polymerase (GENEI Pvt. Ltd. Bangalore, India). The PCR profile was : $94^{\circ} \mathrm{C}$ for 5 minute, followed by 40 cycles of $94^{\circ} \mathrm{C}$ for 1 minute, $55^{\circ} \mathrm{C}$ for 1 minute, $72^{\circ} \mathrm{C}$ for 1 minute and finally by 5 minute at $72^{\circ} \mathrm{C}$ for the final extension. Annealing temperature was adjusted based on the specific requirement of each primer. The PCR reaction was carried out in a PTC 100TM Thermocycler (MJ Research, Sanfrancisco, USA).

PCR products were electrophoresised in 3\% agarose gel (GENEI Pvt. Ltd. Bangalore, India) with 1X TBE buffer, stained with ethidium bromide (EtBr) using and visualized under UV in a gel documentation system (Alpha Innotech,USA).

\section{DATA ANALYSIS}

\section{Morphological Data}

The multi state data scored on 31 morphological traits were used to analyze the Genetic similarities among 13 rice varieties based on simple matching coefficient using NTSYS-PC version 2.02I (Rohlf, 1998). The resulting similarity matrix was first subjected to cluster analysis by the unweighted pair-group method with the arithmetic average (UPGMA) method using sequential agglomerative hierarchical nested cluster analysis (SHAN) programme. A phenetic tree was 
constructed using the TREEPLOT programme of NTSYS pc.

\section{Molecular Data}

The amplified bands were scored as binary data of 1 (present) and 0 (absent) for each primer and was used to construct a dendrogram. The genetic associations between varieties were evaluated by calculating the Jaccard's similarity coefficient for pair wise comparisons based on the proportions of shared bands produced by primers (Jaccard, 1908). Similarity matrix was generated by using the NTSYS-pc software (Rohlf, 1998). The similarity coefficients were used for cluster analysis and dendrogram was constructed by the unweighted pair-group method with arithmetic average (UPGMA). Polymorphism information content (PIC) a measure of the allelic diversity at a locus, was determined as PIC $=1-\Sigma P i^{2}$ where $P \mathrm{i}$ is the frequency of the $\mathrm{i}^{\text {th }}$ allele in the examined test line.

\section{RESULTS AND DISCUSSION}

In the present study 13 rice varieties which are in the commercial cultivation and so in the side chain of Tamil Nadu, India was characterized using morphological and molecular markers to provide useful information to distinguish a variety from other varieties which could be used in seed genetic purity assessment.

\section{Morphological Characterization}

The DUS descriptors developed by Protection of Plant Varieties and Farmers Right Authority (PPV\&FRA) of India were used for characterization of the varieties. Among the 31 descriptors studied some of the plant characters like basal leaf sheath colour, leaf anthocyanin coloration, anthocyanin coloration of auricles, shape and color of legality, anthocyanin colour of internodes, presence of awns, panicle secondary branching, showed no variation among the varieties.

The traits like intensity of leaf colour, flag leaf attitude of blade and panicle curvature of main axis showed noticeable variation. The light green leaves of White Ponni differentiated it from other varieties. Likewise the horizontal flag leaf attitude distinguished Bhavani and CO 48 from other varieties. The varieties ADT 37 and ADT 46 exhibited deflexed panicle curvature among the thirteen varieties while all other showed drooping type panicles. The grain characters like grain length, width and decorticated grain shape showed clear variation among the varieties. The level of demarcation was high in this quantitative grain characters compared to qualitative characters as there is a high chance of merging of their states of expression as they are continuous or discrete giving room for human error. Based on the decorticated grain shape the varieties were grouped as short bold, long bold, medium slender and long slender varieties.

\section{Cluster Analysis}

Cluster analysis based on morphological characters of 13 rice varieties using NTSYS simple matching coefficient showed two major clusters at about $80 \%$ similarity level (Figure 1). Similarity indices estimated based on all the 31 descriptors ranged from 0.52 to 0.90 . Among the two major clusters, cluster I consisted of short bold grain type varieties viz., ADT 37, ASD 16 and CR 1009. The cluster II consisted of medium and long, slender grain type varieties viz., ADT 43, CO 43, IR 50, CO 48, CO 49, CO 50, IR 20, ADT 46, Bhavaini and IW ponni. Katsuta and Okuno (1992) also showed that the local varieties in northern Pakistan are typically classified into two groups, based on the shape of grain. This clearly indicates that those characters, which clearly delineate the varieties, form the basis of distinguishability. 


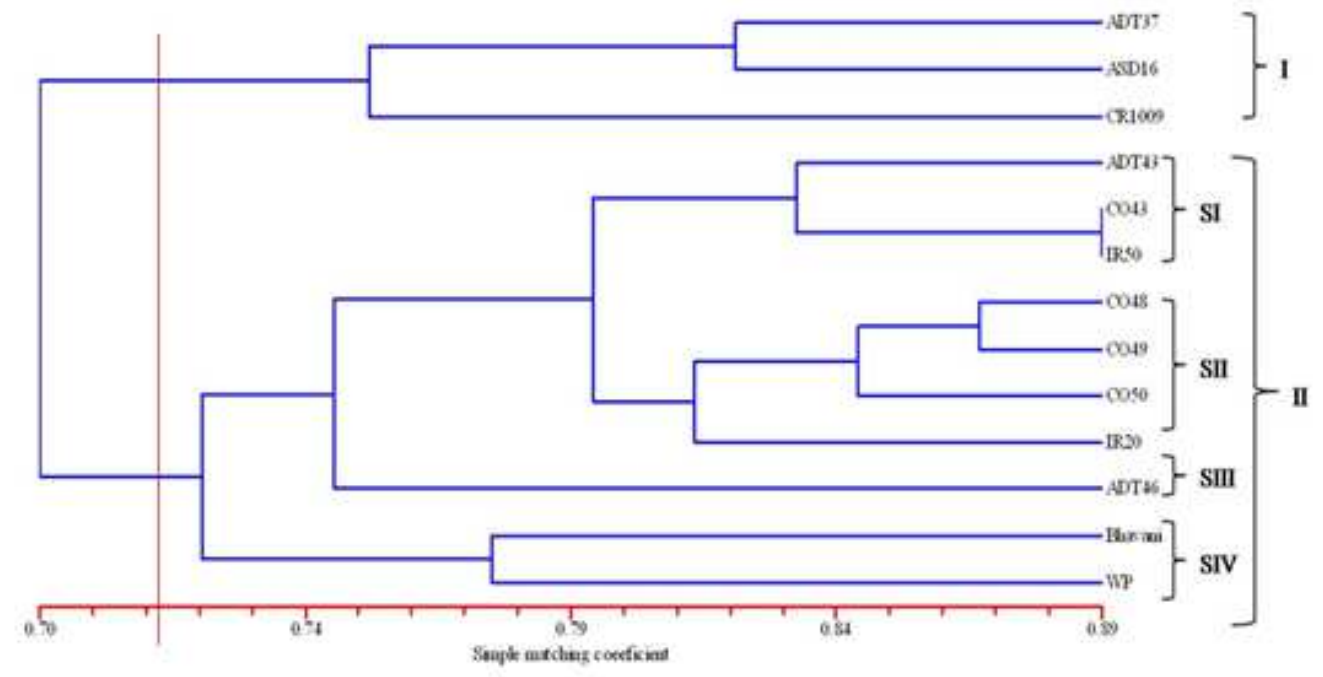

Figure 1: UPGMA Cluster Analysis of 13 Paddy Varieties based on Morphological Characters using Simple Matching Coefficient

The dendrogram based on simple matching co-efficient showed maximum similarity co-efficient of 0.90 between the varieties CO 43 and IR 50. The minimum similarity co-efficient of 0.52 between the varieties ADT 46 and ASD 16 showed that these varieties were phenotypically diverse among all other varieties. The average similarity index of 0.79 indicated remarkable homogeneity among the rice cultivars for the morphological characters studied. Other than the high similarity level of morphological markers, they also influenced by environmental factors. So the purpose of distinguishing the closely related varieties can be fine tuned only when it is supported by a parameter which is stable in all environments like molecular markers. Due to the proliferation of many varieties in all major crop species, however, the number of combinations of morphological and physiological descriptors available to establish the uniqueness of a variety has narrowed down. The necessity of employing the suitable molecular markers for further discrimination of the varieties and to better exploit the diversity is rightly quoted by Zapioca et al. (2010).

\section{Molecular Characterization}

The establishment of the DNA fingerprint database provides the scientific basis for the rice seeds quality supervision and intellectual property protection. The efficacy of SSR markers in determining the degree of relatedness and to detect duplications and seed mixtures was reported by (Yang et al., 1994) and (Olufowote et al., 1997).

\section{SSR Marker Polymorphism Among the Rice Genotypes}

In the present study more than 200 markers were screened and out of which 88 markers that showed polymorphism were used for further analysis. The number of alleles generated by the polymorphic loci varied from 2 - 6 with an average of 2.7 alleles per locus. The average number of alleles detected in the present study was in concordance with Zhu et al. (2012). However the proportion of alleles noticed in the present study was relatively lower than that reported by Rajendran et al. (2012) who observed an average of 4.7, 3.2, alleles per locus using traditional varieties of medicinal rice varieties of India, hybrid rice parental lines, respectively. The reason for lesser number of alleles in this 
study might be due to the varieties of narrow genetic background. Since new cultivars normally arise from hybridizations between members of an elite group of genetically similar parents, the amount of genetic variability among newly developed cultivars is likely to become even smaller (Rahman et al., 2009).

Among the 88 polymorphic markers 45 amplified two alleles each, 30 produced three alleles each, nine produced four alleles each, three produced five alleles each and one marker (RM 5638) produced six alleles. Among the 12 chromosomes, maximum number of alleles (3 - 3.5) was exhibited by Chromosome 4, 1, 2 and 9 while minimum alleles (2.1) were recorded in chromosome 6. However, controversial reports were given by Singh et al. (2004) in rice. This may be due to difference in number of polymorphic primers in each chromosome and also due to the genotype variation of variety selected for the study. The size range between the smallest and the largest allele for the studied microsatellite locus varied between 90 (RM 85) to 415 (RM 422) bp. Figure 2 shows a gel image of amplified fragments produced by polymorphic primers RM 85, RM 163 and RM 228. Some variety specific alleles were identified in locus RM 1880 (ADT 37), RM 228 (ASD 16) and RM 6902 (CR 1009).

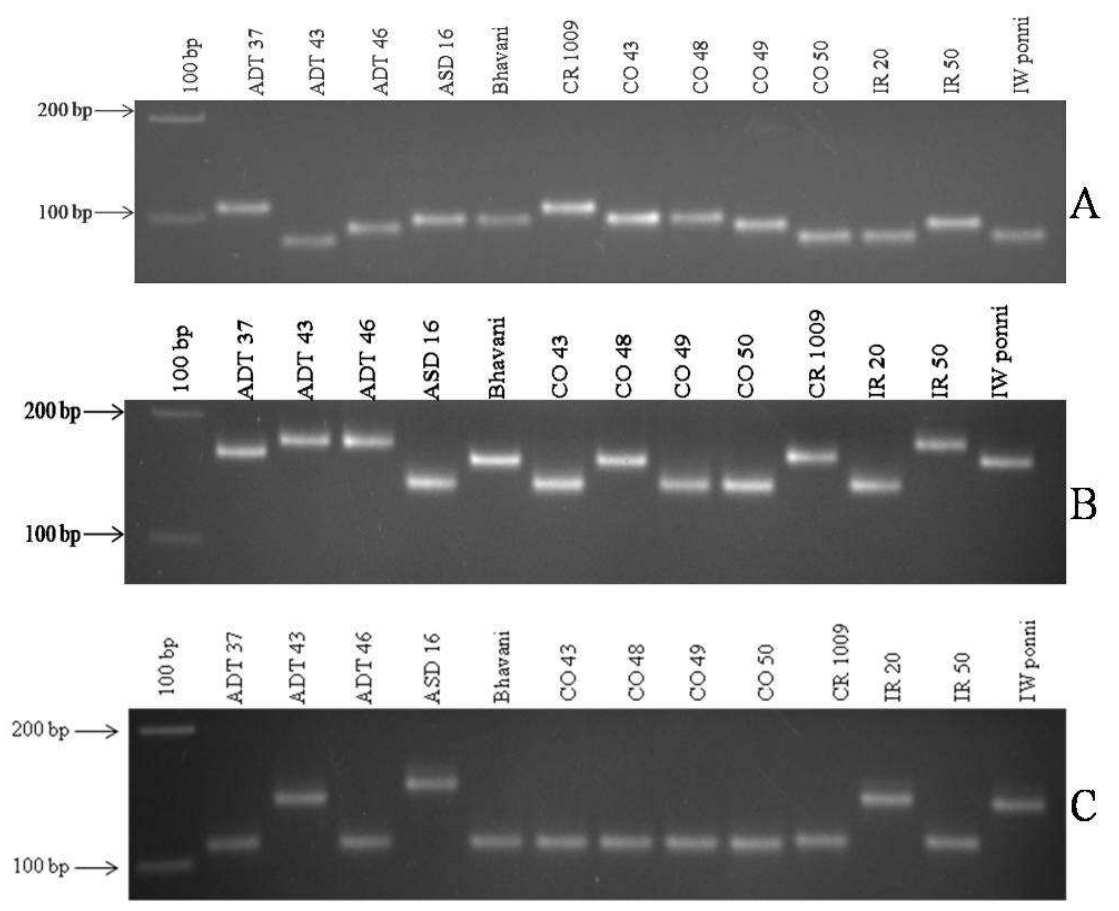

Figure 2: Banding Pattern of 13 Rice Genotypes for RM 85 (A), RM 163(B) and RM 228(C)

\section{Polymorphism Information Content}

The level of polymorphism among 13 rice cultivars was determined by calculating PIC values for each of the 88 SSR loci which showed polymorphism. The PIC value is an indicator that reflects allele diversity and frequency among various rice varieties. In the present work the PIC value ranged from 0.142 to 0.792 with an average of 0.453 , which was similar to Sajib et al. (2012) in aromatic rice where they observed a PIC value of 0.14 to 0.71 with the average PIC value of 0.48. But it is lower than the results reported by Rathi and Sarma (2012) reported in glutinous rice landraces of Assam. Among the primers, RM 245 is highly informative since it recorded highest PIC value (0.792) (Table 2). 
Table 1: List of Rice Varieties and their Pedigree used for Morphological and Molecular Characterization

\begin{tabular}{|c|c|c|c|c|c|}
\hline S.No & Variety & Year of Release & \multicolumn{3}{|c|}{ Parentage } \\
\hline 1 & ADT 37 & 1987 & BG 280 - 12 & $\mathrm{x}$ & PTB 33 \\
\hline 2 & ADT 43 & 1998 & IR 50 & $\mathrm{x}$ & IW ponni \\
\hline 3 & ADT 46 & 2002 & ADT 38 & $\mathrm{x}$ & CO 45 \\
\hline 4 & ASD 16 & 1986 & ADT 31 & $\mathrm{x}$ & CO 39 \\
\hline 5 & Bhavani & 1973 & Peta & $\mathrm{x}$ & BPI 76 \\
\hline 6 & CO 43 & 1982 & Dasal & $\mathrm{x}$ & IR 20 \\
\hline 7 & CO 48 & 2007 & CO 43 & $\mathrm{x}$ & ASD 19 \\
\hline 8 & CO 49 & 2008 & C 20 & $\mathrm{x}$ & RNR 52147 \\
\hline 9 & CO 50 & 2010 & CO 43 & $\mathrm{x}$ & ADT 38 \\
\hline 10 & CR 1009 & 1982 & Pankaj & $\mathrm{x}$ & Jagannath \\
\hline 11 & IR 20 & 1969 & IR 262 & $\mathrm{x}$ & TKM 6 \\
\hline 12 & IR 50 & 1989 & IR-2153-14-1-6-2 & $\mathrm{x}$ & IR 28 X IR 36 \\
\hline 13 & IW Ponni & 1986 & Taichung 65/2 & $\mathrm{x}$ & Mayang Ebos-80 \\
\hline
\end{tabular}

Table 2: Details of the Polymorphic Microsatellite Markers with PIC Values > 0.6

\begin{tabular}{|c|l|l|l|c|c|c|}
\hline S.No. & Locus & Chr.Location & \multicolumn{1}{|c|}{ Ssr Motifs } & $\begin{array}{c}\text { Size Range } \\
(\mathbf{B p s})\end{array}$ & $\begin{array}{c}\text { Number of } \\
\text { Alleles }\end{array}$ & $\begin{array}{c}\text { Pic Value } \\
\left(\mathbf{1}-\mathbf{\Sigma} \mathbf{p i}^{\mathbf{2}}\right)\end{array}$ \\
\hline 1 & RM 226 & 1 & (AT)38 & 274 & 4 & 0.746 \\
\hline 2 & RM 243 & 1 & (CT)18 & 116 & 4 & 0.698 \\
\hline 3 & RM 3652 & 1 & (AG)14 & 107 & 4 & 0.746 \\
\hline 4 & RM 5638 & 1 & (AAG)13 & 203 & 6 & 0.663 \\
\hline 5 & RM 3316 & 2 & (CT)14 & 207 & 3 & 0.651 \\
\hline 6 & RM 3515 & 2 & (CT)28 & 196 & 5 & 0.781 \\
\hline 7 & RM 85 & 3 & (TGG)5(TCT)12 & 208 & 5 & 0.757 \\
\hline 8 & RM 570 & 3 & (AG)15 & 216 & 4 & 0.675 \\
\hline 9 & RM 252 & 4 & (CT)19 & 124 & 4 & 0.675 \\
\hline 10 & RM 163 & 5 & (GGAGA)4(GA)11C(GA)20 & 140 & 3 & 0.710 \\
\hline 11 & RM 210 & 8 & (CT)23 & 202 & 4 & 0.651 \\
\hline 12 & RM 219 & 9 & (CT)17 & 150 & 5 & 0.722 \\
\hline 13 & RM 245 & 9 & (CT)14 & 213 & 4 & 0.793 \\
\hline 14 & RM 222 & 10 & (CT)18 & 157 & 4 & 0.698 \\
\hline 15 & RM 21 & 11 & (GA)18 & & & 0.663 \\
\hline
\end{tabular}

\section{UPGMA Cluster of the 13 Rice Cultivars based on SSR Analysis}

The genetic relationships between the rice varieties were assessed by cluster analysis of the similarity matrix derived from the loci generated by the SSR markers. The similarity index based on 88 microsatellite marker loci ranged from 0.23 to 0.50 with the average similarity index of 0.35 . UPGMA clustering dendrogram generated for 13 paddy varieties showed four major clusters at a similarity index of 0.35 (Figure 3).

Cluster I was the largest which included 6 varieties, viz., ADT 37, CO 43, CO 50, IR 20, Bhavani and CO 48. In this cluster the varieties CO 50 and IR 20 were found to be closely related with the similarity index of 0.50 . The pedigree of CO 48, CO 50 clearly shows that they share the same parent CO 43 which is a cross between Dasal and IR 20 . So CO 43, CO 48, CO 50 and IR 20 share the same cluster I. The cluster II includes only one variety i.e improved white ponni while clusters III and IV were of equal size, comprising 3 varieties each. Cluster III consists of ADT 43, ADT 46 and IR 50. The varieties ADT 43 and IR 50 share the same cluster as IR 50 is one of the parent of ADT 43 . The fourth cluster contains varieties like ASD 16, CO 49 and CR 1009. The data on pedigree of ASD 16 and CR 1009 shows Peta as one of their parents. Thus the relationship between the clustering pattern and the pedigree of the thirteen rice varieties was 
obvious in this study. Previously Bansal et al. (1990) also reported about the influence of the pedigree of the breeding lines on the clustering pattern.

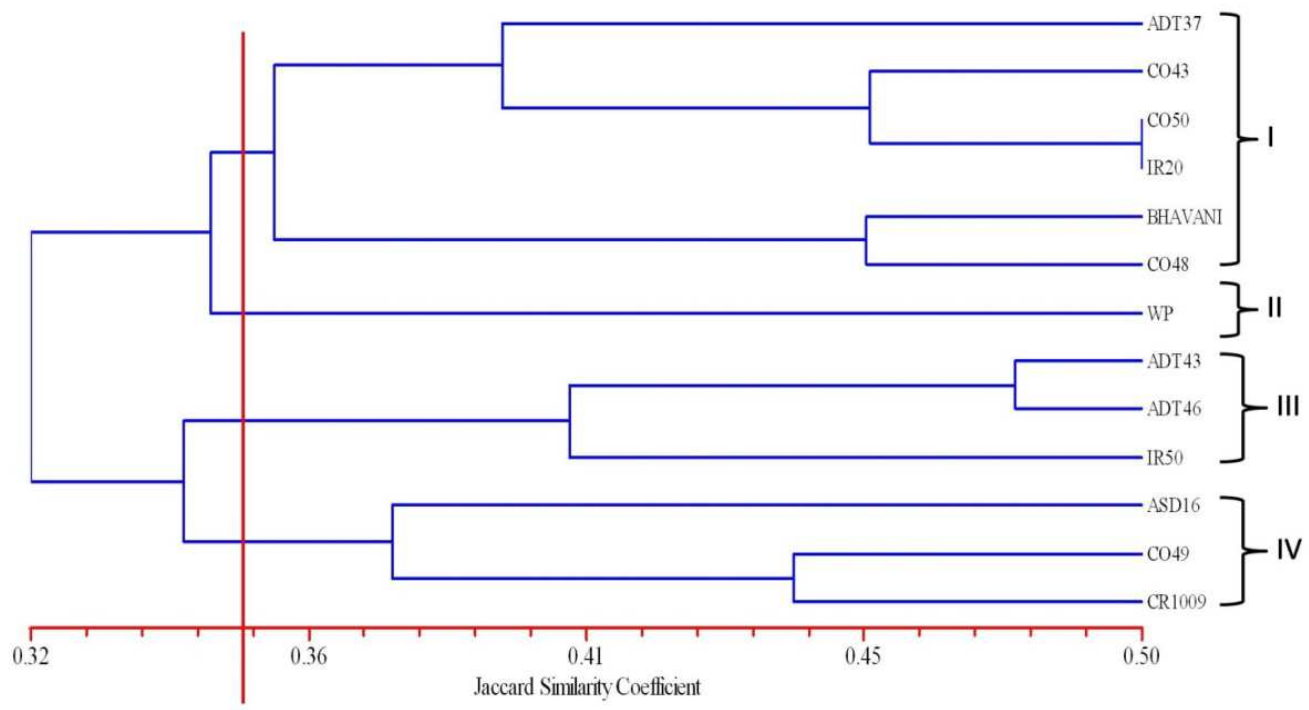

Figure 3: UPGMA Cluster Analysis of 13 Paddy Varieties based on SSR Analysis using Jaccard's Similarity Co-Efficient

\section{CONCLUSIONS}

The average similarity index of 0.65 for morphological data and 0.35 for SSR data apparently defines the advantage of SSR over morphology in unambiguous and quick identification of closely related varieties. The database created using SSR markers can be used as a tool in seed testing laboratories to assess the genetic purity of seed lots under question, as a measure of seed quality control.

\section{REFERENCES}

1. Agarwal, R.K., Brar, D.S., Nandi, S., Huang, N., \& Khush, G.S. (1999). Phylogenetic relationships among Oryza species revealed by AFLP markers. Theoretical Applied Genetics, 98 (8), 1320-1328.

2. Bansal, M.P., Panwar, D.V.S., \& Naidu, M.R. (1990). Genetic divergence among the breeding lines of diverse crosses of rice. Res. Develop. Rep., 7, 90-96.

3. Dellaporta, S.L., Wood, T., \& Hicks, T.B., (1983). A plant DNA mini preparation: version II. Plant Mol. Biol. Rep., 1,19-21.

4. Jaccard, P. (1908). Nouvelles researches sur la distribution florale. Bull Soc. Vaud. Sci. Nat. 44, 233-270.

5. Katsuta, M., \& Okuno, K. (1992). Rice cultivars in Northern Pakistan. Japan J. Breed., 42, 707-713.

6. Olufowote, J.O., Xu, Y., Chem, X., Park, W.D., Beachell, H.M., Dilday, R.H., Goto, M., \& McCouch, S.R. (1997). Comparative evaluation of within cultivar variation of rice (Oryza sativa L) using microsatellite and RFLP markers. Genome, 40, 370-378.

7. Panaud, O., Chen, X., \& McCouch, S.R. (1996). Development of microsatellite markers and characterization of simple sequence length polymorphism (SSLP) in rice (Oryza sativa L). Mol. Gen. Genet., 252, 597-607.

8. Rahman, M.S., Molla, M.R, Alam, M.S., \& Rahman, L. (2009). DNA fingerprinting of rice (Oryza sativa L) cultivars using microsatellite markers. Aust. J. Crop Sci., 3(3), 122-128. 
9. Rajendran, N., Mukherjee, L., Reddy, K.K., \& Shashidhar, H.E.Z. (2012). DNA fingerprinting and estimation of genetic diversity among hybrid rice parental lines (Oryza sativa L) using simple sequence repeats (SSR) markers. Journal of Plant Breeding and Crop Science, 4(11), 169-174.

10. Rathi, S., \& Sarma, R.N. (2012). Microsatellite diversity in indigenous glutinous rice landraces of Assam. Indian Journal of Biotechnology, 11, 23-29.

11. Ravi, M., Geethanjali, S., Sameeyafarheen, F., \& Maheswaran, M. (2003). Molecular Marker based Genetic Diversity Analysis in Rice (Oryza sativa L) using RAPD and SSR markers. Euphytica, 133, 243-252.

12. Rohlf FJ (1998). NTSYS-pc Numerical Taxonomy and Multivariate Analysis System, version 20, Exeter Software, Setauket, New York.

13. Sajib, A.M., Hossain Md, M., Mosnaz,A.T.M.J., Hossain, H., Islam Md, M., Ali Md, S., \& Prodhan, S.H. (2012). SR markerbased molecular characterization and genetic diversity analysis of aromatic landraces of rice (Oryza sativa L). J. Bio. Sci. Biotech, 1(2), 107-116.

14. Singh, R.K., Sharma, R.K., Singh, A.K., Singh, V.P., Singh, N.K., Tiwari, S.P., \& Mohapatra, T. (2004). Suitability of mapped sequence tagged microsatellite site markers for establishing distinctness, uniformity and stability in aromatic rice Euphytica, $135,135-143$.

15. Yang, G.P., Maroof, M.A.S., Xu, C.G., Zhang, Q., \& Biyashev, R.M. (1994). Comparative analysis of microsatellite DNA polymorphism in land races and cultivars of rice. Mol. Gen. Genet., 245, 187-194.

16. Zhu, Y.F., Qin, G.C., Hu, J., Wang, Y., Wang, J., \& Zhu, S.J. (2012). Fingerprinting and variety identification of rice (Oryza sativa L) based on simple sequence repeat markers. POJ, 5(4), 421-426.

17. Zapico F. C. L., J. A. Namocatcat and J. L.C. Turner. 2010. Genetic Diversity Analysis of Traditional Upland Rice Cultivars in Kihan, Malapatan, Sarangani Province, Philippines Using Morphometric Markers. Philippine Journal of Science, 139(2): $177-180$. 